\title{
Pengaruh Teknik Ice Breaking Dalam Bimbingan Kelompok Untuk Mengurangi Kejenuhan Belajar Mahasiswa
}

\author{
Rosliana \\ Institut Pemerintahan Dalam Negeri, Indonesia \\ Email: roslianahochi4@gmail.com
}

\begin{abstract}
Abstrak. Tujuan penelitian ini adalah untuk (1) Mengetahui gambaran pelaksanaan teknik ice breaking di Institut Pemerintahan Dalam Negeri Sulawesi Selatan (2) Mengetahui gambaran tingkat kejenuhan belajar mahasiswa sebelum dan sesudah diberikan teknik ice breaking di Institut Pemerintahan Dalam Negeri Sulawesi Selatan. (3) Mengetahui apakah ada pengaruh teknik ice breaking dapat mengurangi tingkat kejenuhan belajar mahasiswa di Institut Pemerintahan Dalam Negeri Sulawesi Selatan.Penelitian ini menggunakan pendekatan eksperimen (True Experimental Designs) dalam bentuk Pretest-Posttest Control Group Design. Teknik pengumpulan data melalui angket, dan observasi. Analisis data menggunakan analisis statistic deskriptif non parametric wilcoxon signed ranks test. Sampel kelompok eksperimen 15 praja dan sampel kelompok kontrol 15 praja. Hasil penelitian menunjukkan bahwa: (1) Pelaksanaan teknik ice breaking dalam bimbingan kelompok dilakukan melalui tahap persiapan, tahap peralihan, pelaksanaan kegiatan dan tahap pengakhiran termasuk pretest dan posttest. Pelaksanaan ice breaking,mahasiswa mengikuti dengan antusias serta aktif berpartisipasi dalam setiap permainan yang diberikan. (2) Tingkat kejenuhan belajar mahasiswa di Institut Pemerintahan dalam Negeri Sulawesi Selatan sebelum diterapkan teknik ice breaking dalam bimbingan kelompok berada pada kategori sangat tinggi,dan setelah diterapkan teknik ice breaking dalam bimbingan kelompok berada pada kategori rendah (3) Ada pengaruh yang signifikan terhadap penerapan teknik ice breaking dalam bimbingan kelompok dalam mengurangi kejenuhan belajar mahasiswa di Institut Pemerintahan dalam Negeri Sulawesi Selatan. Artinya, teknik ice breaking dalam bimbingan kelompok dapat mengurangi kejenuhan belajar mahasiswa.
\end{abstract}

Kata kunci : Ice Breaking, Kejenuhan Belajar

Abstract. The purpose of this study was to (1) Know the description of the implementation of the ice breaking technique at the Institute of Internal Administration of South Sulawesi (2) To determine the description of the level of student learning saturation before and after being given ice breaking technique at the Institute of Internal Administration of South Sulawesi. (3) Determine whether there is an effect that ice breaking technique can reduce the level of boredom of student learning at the Institute of Internal Administration of South Sulawesi. This study uses an experimental approach (True Experimental Designs) in the form of a Pretest-Posttest Control Group Design. Data collection techniques through questionnaires, and observation. Data analysis used descriptive statistical analysis nonparametric Wilcoxon signed ranks test. The sample of the experimental group was 15 students and the control group sample was 15 students. The results showed that: (1) The implementation of the ice breaking technique in group guidance was carried out through the preparation stage, the transitional stage, the implementation of activities and the closing stage including the pretest and posttest. During the ice breaking, students participated enthusiastically and actively participated in every game that was given. (2) The level of learning saturation of students at the Institute of Internal Administration of South Sulawesi before the application of the ice breaking technique in group guidance was in the very high category, and after the application of the ice breaking technique in group guidance was in 
the low category (3) There was a significant effect on the application. ice breaking techniques in group guidance in reducing boredom of student learning at the Institute of Internal Government of South Sulawesi. That is, ice breaking techniques in group guidance can reduce student learning boredom.

Keywords: Ice Breaking, Learning Saturation

Ini adalah artikel dengan akses terbuka dibawah licenci $C C B Y-N C-4.0$ (c) (i) () (https://creativecommons.org/licenses/by-nc/4.0/)

\section{PENDAHULUAN}

Institut Pemerintahan Dalam Negeri Sulawesi Selatan sebagai sekolah pendidikan tinggi kepamonprajaan keberadaan mahasiswa sebagai kader-kader mahasiswa selain mendapatkan berbagai materi perkuliahan juga mendapatkan materi pelatihan disetiap semester sesuai dengan kalender akademik, diharapkan para mahasiswa dapat mempelajari bagaimana proses pemerintahan, pembangunan dan kemasyarakat baik pada tingkat desa/kelurahan, kecamatan dan kabupaten juga dapat mengaplikasikan berbagai materi pelatihan yang didapatkan disetiap tingkatan, sehingga para mahasiswa tidak hanya siap secara teori tetapi secara praktekpun juga sudah dapat dikuasai. Institit pemeritahan dalam negeri yang merupakan lembaga pendidikan kedinasan yang mempersiapkan kader-kader pemerintahan dengan penyelenggaraan pendidikan dilaksanakan dengan sistem, pengajaran, pelatihan, dan pengasuhan (JARLATSUH).

Institut Pemerintahan Dalam Negeri Sulawesi Selatan sebagai sekolah pendidikan tinggi kepamongprajaan dimana keberadaan mahasiswa tidak hanya disiplin tapi siap bekerja mengaplikasikan ilmu baik terori maupun praktek sebagai mahasiswa yang nantinya siap ditempatkan baik di dalam rangka menjalankan tugas pemeritahan dan pembangunan baik ditingkat daerah maupun ditingkat pusat secara berdaya guna dan berhasil guna. Sehingga perlu diusahakan kondisi yang bebas dari kelelahan dan mengusahakan agar para mahasiswa belajar dalam kondisi yang riang. Sementara ketegangan mental tersebut bisa timbul dari beban pelajaran yang terlalu berat, target untuk mencapai prestasi yang tinggi, dosen yang terlalu galak, dan hal-hal lain yang menimbulkan ketegangan mental.

Kelelahan pada seseorang walaupun sulit untuk dipisahkan tetapi dapat dibedakan menjadi dua macam, yaitu kelelahan fisik dan psikis.
Kelelahan fisik terlihat dari lemahnya tampilan fisik dan timbul kecenderungan untuk membaringkan tubuh. Kelelahan fisik terjadi karena tidak normalnya sisa pembakaran di dalam tubuh, sehingga aliran darah kurang lancar pada bagian-bagian tertentu. Hal tersebut kerap kali memicu kondisi tubuh yang mudah merasa lelah, emosional dan tidak bersemangat. Sedangkan kelelahan psikis dapat dilihat dengan adanya kelesuhan dan kebosanan, sehingga minat dan dorongan untuk menghasilkan sesuatu akan hilang (tidak produktif). Adapun gejala kejenuhan belajar berupa sakit kepala, sulit tidur, cepat merasa lelah, mudah panik, mudah marah, sulitnya berkomunikasi dengan oranglain, mengurung diri dikamar, percaya diri menurun serta mudah mengalami kebosana, Fatmawati (2018). Kelelahan ini sangat terasa pada bagian kepala dengan adanya gejala pusing-pusing sehingga sulit untuk berkonsentrasi, seolah-olah otak kehabisan daya untuk bekerja. Salah satu yang dapat di lakukan adalah pemberian teknik Ice breaking sebagai solusi dalam mengatasi kejenuhan belajar mahasiswa.

Ice breaking yang diberikan kepada mahasiswa dalam bentuk kegiatan bermain. Kegiatan permainan ini diberikan dalam bentuk bermain kelompok. Permainan yang di terapkan memiliki nilai kepemimpinan, kerjasama tim, kreatifitas dan konsentrasi belajar. Kegiatan ini dapat meningkatkan konsentrasi mahasiswa dalam belajar karena menyajikan permainan yang menarik sehingga menjadi rileks, bersemangat, tidak membuat mengantuk, serta ada perhatian dan ada rasa senang untuk mendengarkan atau melihat orang yang berbicara di depan kelas atau ruangan pertemuan.

Fanani (2010) mendefenisikan ice breaking adalah sentuhan aktivitas yang dapat digunakan untuk memecahkan kebekuan, kekalutan, kejemuan dan kejenuhan suasana sehingga menjadi mencair dan suasana bisa kembali pada keadaan semula (lebih kondusif). 
Jika sentuhan aktivitas ini diterapkan pada proses pembelajaran di kelas, maka besar kemungkinannya siswa kembali pada kondisi (semangat, motivasi, gairah belajar, kejemuan dan lain sebagainya) yang lebih baik. Ice breaking merupakaan suatu aktivitas kecil dalam suatu kegiatan yang bertujuan agar individu mengenal yang lain dan merasa (Syam Mahfud, 2010). Sementara menurut Suryoharjuno (2012) menguraikan defenisi Ice breking yaitu peralihan situasi dari membosankan, mengantuk, menjemukan, dan tegang menjadi rileks, bersemangat, tidak membuat mengantuk, serta ada perhatian dan ada rasa senang untuk mendengarkan atau melihat orang yang berbicara di depan kelas atau ruangan pertemuan. ice breaker adalah sebuah kegiatan belajar yang dinamis, penuh semangat yang berfungsi untuk memecah kebekuan dan membangkitkan motivasi belajar siswa sehingga terciptanya suatu kondisi belajar yang menyenangkan, Kurniasih(2015).

Berdasarkan hasil defenisi di atas, dapat di simpulkan bahwa ice breaking merupakan suatu aktivitas kelompok dalam suatu kegiatan permainan sebagai usaha untuk memecah suasana tegang atau kaku agar peserta didik dapat membangun interaksi dan komunikasi secara langsung serta terciptan suasana santai, nyaman dengan keadaan lingkungannya.

Pemberian teknik ice breaking dalam bentuk kegiatan bermain, dapat meningkatkan konsentrasi mahasiswa dalam belajar karena permainan melalui ice breaking ini dapat menciptakan suasana yang tidak tegang dalam berinteraksi, membosankan dalam belajar dan akan ada fokus perhatian dan ice breaking dalam bentuk permainan efektif meningkatkan keterampilan sosial siswa (Bakhtiar, 2015). Ice breaking sebagai teknik bimbingan kelompok diupayakan sebagai teknik untuk mengurangi kejenuhan belajar mahasiswa, karena dengan Ice breaking mahasiswa dapat belajar sesuatu tanpa mempelajarinya yang dilakukan melalui sikap saling bekerjasama dan diskusi kelompok, untuk memainkan sebuah permainan yang di lakukan secara bersama-sama. Hasil penelitian yang dilakukan oleh Sumardani(2014) bahwa penerapan teknik Ice Breaker memberikan pengaruh yang sedang terhadap hasil belajar peserta didik pada mata pelajaran Matematika di kelas III Sekolah Dasar Negeri 20 Pontianak Selatan. Hasil penelitian lain menunjukkan bahwa kreativitas guru dalam menerapkan ice breaking saat proses pembelajaran berpengaruh terhadap hasil belajar siswa yang mencerminkan motivasi belajar siswa, Febrianri \& dkk (2018). Oleh karena itu, Ice breaking di yakini sangat cocok di terapkan dalam membantu mahasiswa mengatasi masalah kejenuhan belajarnya. Ice breaking adalah sarana yang mampu menjadi solusi tetap dan tepat, karena permainan ice breaking mengambil peran mediasi sekaligus mereduksi. Penyatuan pola pikir dan pola tindak ke satu titik perhatian adalah hal yang bisa membuat suasana menjadi terkondisi untuk dinamis dan fokus (Soenarno, 2007).

Pelaksaan teknik ice breaking dapat dilakukan dalam bentuk bimbingan kelompok. Bimbingan kelompok adalah layanan bimbingan yang diberikan dalam suasana kelompok. Bimbingan kelompok adalah bantuan terhadap individu yang dilaksanakan dalam situasi kelompok, bimbingan kelompok berupa penyampaian informasi atau aktivitas kelompok membahas masalah-masalah pendidikan, pekerjaan, pribadi dan sosial (Nurihsan,2006). Bimbingan kelompok adalah layanan bimbingan yang diberikan kepada siswa dalam situasi kelompok dengan dipimpin oleh guru bimbingan dan konseling, layanan bimbingan kerlompok cenderung tidak dilaksanakan karena lebih menggunakan media papan bimbingan dalam memberikan layanan, jika memberikan layanan bimbingan kelompokpun layanan tersebut masih (cenderung) bersifat kasuistik atau insidental, Setianingsih \& dkk (2014.

Secara harfiah jenuh adalah padat atau penuh sehingga tidak mampu lagi memuat apapun. Selain itu juga jenuh dapat berarti jemu atau bosan, juga terkadang mengalami peristiwa negatif yang disebut jenuh dalam belajar atau dalam istilahnya lebih dikenal dengan sebutan "learning plateu/plateam". Kejenuhan belajar adalah "suatu kondisi mental seseorang saat mengalami rasa bosan dan lelah sehingga mengakibatkan timbulnya rasa enggan, lesu, tidak bersemangat, atau tidak bergairah melakukan aktivitas dalam belajar (Hakim, 2000). Kejenuhan belajar merupakan suatu bentuk kesulitan belajar yang tidak mudah untuk diatasi. Sugara (2011) mengemukakan bahwa dampak dari kejenuhan belajar adalah menjadikan siswa tidak produktif dalam belajar dan potensi yang dimilikinya terhambat.

Kejenuhan belajar yang dialami mahasiswa harus diberikan penanganan secara dini agar tidak berdampak negatif terhadap kesuksesan belajar di Institut Pemerintahan Dalam Negeri Sulawesi Selatan. Oleh karena itu 
diharapkan agar mahasiswa mampu membagi antara suasana santai dan serius ataupun bermain dan belajar serta mampu bertanggung jawab atas segala konsekuensi yang telah diperbuatnya sendiri. Sehingga mahasiswa diharapkan memiliki kemampuan untuk mengontrol diri dalam belajar.

Berdasarkan hasil observasi dan wawancara awal yang dilakukan oleh peneliti terhadap mahasiswa di Institut Pemerintahan Dalam Negeri (IPDN) Sulawesi Selatan pada tanggal 3 November 2014 ditemukan bahwa ada 15 mahasiswa terindikasi mengalami kejenuhan belajar. Hal ini ditandai dengan sikap mahasiswa yang acuh tak acuh dalam mengikuti pelajaran, tidak memperhatikan dosen saat menjelaskan, mengantuk dan tidak bergairah. Semakin diperkuat lagi dari hasil wawancara yang dilakukan kurang lebih dari delapan mahasiswa di Institut Pemerintahan Dalam Negeri (IPDN) Sulawesi Selatan, diperoleh informasi adanya mahasiswa yang mengalami kejenuhan belajar. Gejala-gejala kejenuhan yang dialami mahasiswa tersebut berkaitan dengan aktivitas belajarnya yang cukup membosankan. Kondisi tersebut jika tidak ditangani akan dapat berdampak terhadap rendahnya kemampuan belajar mahasiswa dan berakhir pada prestasi mahasiswa yang kian menurun.

Mencermati pentingnya ice breaking sebagai upaya mengurangi kejenuhan belajar pada mahasiswa, maka penulis menganggap bahwa permasalahan inilah yang akan dijadikan fokus objek penelitian, karena teknik tersebut dapat menjadi salah satu referensi dalam mereduksi kejenuhan belajar yang terjadi pada mahasiswa di Institut Pemerintahan Dalam Negeri (IPDN) Sulawesi Selatan, dan teknik ini belum pernah diterapkan di Institut tersebut melalui kegiatan penelitian. Berkaitan dengan hal di atas, maka penulis melakukan penelitian tentang "Pengaruh Ice Breaking Untuk Mengurangi Kejenuhan Belajar Mahasiswa di Institut Pemerintahan Dalam Negeri Sulawesi Selatan".

\section{METODE}

Pendekatan yang digunakan dalam penelitian ini adalah pendekatan kuantitatif dengan jenis penelitian true eksperimen desain. Sampel penelitian ini sebanyak 30 praja yang terdiri dari 15 kelompok eksperimen dan 15 kelompok konrol, maka teknik sampling yang digunakan adalah simple random sampling. Selanjutnya teknik pengumpulan data yang digunakan yaitu skala kejenuhan belajar dan observasi. Penelitian ini menggunakan Analisis statistik deskriptif dan analisis inferensial. Uji hipotesis dilakukan melalui uji Wilcoxon.

\section{HASIL DAN PEMBAHASAN}

Analisis statistik deskriptif dimaksudkan untuk memperoleh gambaran tingkat kejenuhan belajar mahasiswa di Institut Pemerintahan Dalam Negeri Sulawesi Selatan, baik kelompok eksperimen maupun kelompok kontrol, baik hasil Pretest maupun Posttest.

Tabel 1. Data tingkat kejenuhan belajar Mahasiswa di IPDN Sulawesi Selatan Sebelum (Pretest) dan Setelah (Posttest) Pemberian Teknik Ice Breaking dalam Bimbingan Kelompok.

\begin{tabular}{|c|c|c|c|c|c|}
\hline \multirow{3}{*}{$\begin{array}{c}\text { Interva } \\
1\end{array}$} & \multirow{3}{*}{$\begin{array}{c}\text { Tingkat } \\
\text { Kejenuhan } \\
\text { Belajar }\end{array}$} & \multicolumn{4}{|c|}{ Kelompok Eksperimen } \\
\hline & & \multicolumn{2}{|c|}{ Pretest } & \multicolumn{2}{|c|}{ Postest } \\
\hline & & $\mathbf{F}$ & $\mathbf{P}(\%)$ & $\mathbf{F}$ & $\mathbf{P}(\%)$ \\
\hline $81-99$ & $\begin{array}{l}\text { Sangat } \\
\text { Tinggi }\end{array}$ & 12 & $80 \%$ & - & - \\
\hline $62-80$ & Tinggi & 3 & $20 \%$ & - & - \\
\hline $43-61$ & Rendah & - & - & 10 & $\begin{array}{r}66,66 \\
\% \\
\end{array}$ \\
\hline $24-42$ & $\begin{array}{l}\text { Sangat } \\
\text { Rendah }\end{array}$ & - & - & 5 & $\begin{array}{r}33,33 \\
\% \\
\end{array}$ \\
\hline & Jumlah & 15 & 100 & 15 & 100 \\
\hline
\end{tabular}

Sumber: Hasil skala kelompok eksperimen.

Tingkat kejenuhan belajar mahasiswa di Institut Pemerintahan Dalam Negeri Sulawesi Selatan untuk kelompok eksperimen saat pretest secara umum dalam kategori sangat tinggi sebanyak 12 responden atau 80 persen, kategori tinggi sebanyak 3 responden atau 20 persen. Namun setelah diberikan perlakuan berupa ice breaking sebanyak 5 tahap, maka tingkat kejenuhan belajar mahasiswa menunjukkan perubahan positif yakni penurunan yang berarti, dimana kategori rendah sebanyak 10 responden atau 66,66 persen, kategori sangat rendah sebanyak 5 responden atau 33,33 persen. Hal tersebut diperkuat dengan nilai rata-rata Pretest yaitu $(85,13)$ yang berarti sangat tinggi, sedangkan nilai Posttest dengan rata-rata $(47,93)$ berada pada kategori rendah yang menunjukkan menurunnya tingkat kejenuhan belajar mahasiswa. 
Tabel 2. Data tingkat kejenuhan belajar Mahasiswa IPDN Sulawesi Selatan Sebelum (Pretest) dan Setelah (Posttest) Pemberian Teknik Ice Breaking dalam Bimbingan Kelompok.

\begin{tabular}{cccccc}
\hline \multirow{2}{*}{$\begin{array}{c}\text { Interva } \\
\text { I }\end{array}$} & \multirow{2}{*}{ Kategori } & \multicolumn{3}{c}{ Kelompok Kontrol } \\
\cline { 3 - 6 } & & \multicolumn{2}{c}{ Pretest } & \multicolumn{2}{c}{ Postest } \\
\cline { 3 - 6 } & & F & P(\%) & F & P(\%) \\
\hline $81-99$ & $\begin{array}{l}\text { Sangat } \\
\text { Tinggi }\end{array}$ & 11 & 73,33 & 9 & 60 \\
$62-80$ & Tinggi & 4 & 26,66 & 6 & 40 \\
$43-61$ & Rendah & - & - & - & - \\
$24-42$ & $\begin{array}{c}\text { Sangat } \\
\text { Ren } \\
\text { dah }\end{array}$ & - & - & - & - \\
& Jumlah & 15 & 100 & 15 & 100
\end{tabular}

Sumber : Hasil skala kelompok kontrol

Tingkat kejenuhan belajar mahasiswa untuk kelompok kontrol saat Pretest secara umum berada pada kategori sangat tinggi sebanyak 11 responden atau 73,33 persen, terdapat 4 responden pada kategori tinggi atau 26,66 persen. Namun saat Postest kondisi tersebut tidak menunjukkan perubahan yang berarti, dimana kategori sangat tinggi sebanyak 9 responden atau 60 persen dan kategori tinggi sebanyak 6 responden atau 40 persen.

Hasil uji deskriptif menunjukkan informasi adanya perbedaan dari hasil analisis deskriptif data hasil pre-test dan post-test hasil skala kejenuhan belajar mahasiswa. Hasil deskriptif data pre-test diperoleh nilai mean (ratarata) 78.6000 dari 15 sampel dengan nilai standar deviasi 9.17138 dengan nilai minimum 62.00 serta median 83.0000. Hasil deskriptif data posttest diperoleh data mean (rata-rata) 82.0667 dari 15 sampel dengan nilai standar deviasi 8.45549 dengan nilai minimum 66.00 serta median 85.0000. Dari data hasil pre-test diperoleh mean rata-rata 78.6000 berada pada kategori tinggi, sedangkan data hasil post-test diperoleh mean rata-rata 79.0667 masih dalam kategori yang sama yaitu tinggi berarti tidak ada perubahan signifikan dari hasil pre-test dan hasil post-test.
Tabel 3. Tingkat kejenuhan belajar Mahasiswa di Institut Pemerintahan dalam Negeri Sulawesi Selatan.

\begin{tabular}{ccccc}
\hline $\begin{array}{c}\text { Jenis } \\
\text { Data }\end{array}$ & $\begin{array}{c}\text { Kelompo } \\
\mathbf{k}\end{array}$ & Mean & $\begin{array}{c}\text { Interv } \\
\text { al }\end{array}$ & $\begin{array}{c}\text { Klasifik } \\
\text { asi }\end{array}$ \\
\hline Pretest & $\begin{array}{c}\text { Eksperim } \\
\text { en } \\
\text { Kontrol }\end{array}$ & 85,13 & $81-99$ & $\begin{array}{c}\text { Sangat } \\
\text { tinggi }\end{array}$ \\
Posttest & $\begin{array}{c}\text { Eksperim } \\
\text { en } \\
\text { Kontrol }\end{array}$ & 47,6 & $62-80$ & $\begin{array}{c}\text { Tinggi } \\
\text { Rendah }\end{array}$ \\
& 79.06 & $62-80$ & Tinggi \\
\hline
\end{tabular}

Sumber: hasil pretest dan posttest

Dari data di atas, dapat dilihat bahwa tingkat kejenuhan belajar mahasiswa pada kelompok eksperimen berada pada kategori sangat tinggi dan kelompok kontrol berada pada kategori tinggi pada hasil pretest. Sedangkan pada hasil posttest kelompok ekperimen berada pada ketegori rendah dan kelompok kontrol berada pada kategori yang sama yaitu tinggi, jadi tingkat kejenuhan belajar mahasiswa sebelum dan sesudah diberikan perlakuan memperlihatkan menurunya tingkat kejenuhan belajarnya.

Kelelahan dalam belajar mempengaruhi tingkat semangat belajar masing-masing individu. Oleh karena itu, disarankan kepada mahasiswa untuk menghindari terjadinya kelelahan atau kebosanan dalam belajarnya. Sebab itu, dapat membuat mahasiswa mengalami stress berat. Sehingga perlu diusahakan kondisi yang bebas dari kelelahan dan mengusahakan agar para mahasiswa belajar dalam kondisi yang riang. Sementara ketegangan mental tersebut bisa timbul dari beban pelajaran yang terlalu berat, target untuk mencapai prestasi yang tinggi, dosen yang terlalu galak, dan hal-hal lain yang menimbulkan ketegangan mental. Salah satu yang dapat di terapkan adalah pemberian teknik ice breaking sebagai solusi memecahkan persoalan dalam kejenuhan belajar mahasiswa. Teknik ice breaking yang diberikan pada mahasiswa dalam bentuk kegiatan bermain. Kegiatan permainan ini diberikan dalam bentuk bermain kelompok. Permainan yang di terapkan memiliki nilai kepemimpinan, kerjasama tim, kreatifitas dan konsentrasi belajar. Kegiatan ini dapat meningkatkan konsentrasi siswa dalam belajar karena menyajikan permainan yang menarik sehingga menjadi rileks, bersemangat, tidak membuat mengantuk, serta ada perhatian dan ada rasa senang untuk mendengarkan atau melihat orang yang berbicara di depan kelas atau ruangan pertemuan. Adapun permainan ice 
breaking yang dilaksanakan dalam penelitian ini adalah permainan benar-salah, warisan, gemu fami re, satu hati,dan goyang pingui khatulistiwa. Jenis permainan yang diangkat dalam ice breaking dianggap sudah sesuai dengan kebutuhan mahasiswa dalam meningkatkan konsentrasinya dalam belajar. Dimana masingmasing setiap permainan yang diangkat dalam permaian ice breaking mempunyai tujuan yang sama yaitu untuk meningkatkan kerja sama tim, kreatifitas dan konsentrasi belajar. Kusumo Suryoharjuno (2012) menguraikan Ice breking merupakan peralihan situasi dari membosankan, mengantuk, menjemukan, dan tegang menjadi rileks, bersemangat, tidak membuat mengantuk, serta ada perhatian dan ada rasa senang untuk mendengarkan atau melihat orang yang berbicara di depan kelas atau ruangan pertemuan.

Pemberian teknik ice breaking dalam bentuk kegiatan bermain, dapat meningkatkan konsentrasi siswa dalam belajar karena permainan melalui teknik ice breaking dapat menciptakan suasana yang tidak tegang dalam berinteraksi, membosankan dalam belajar dan akan ada fokus perhatian. Teknik ice breaking sebagai teknik bimbingan kelompok diupayakan sebagai teknik untuk mengurangi kejenuhan belajar siswa, karena dengan teknik ice breaking mahasiswa dapat belajar sesuatu tanpa mempelajarinya yang dilakukan melalui sikap saling bekerjasama dan diskusi kelompok, untuk memainkan sebuah permainan yang di lakukan secara bersama-sama. Oleh karena itu teknik ice breaking di yakini sangat cocok di terapkan dalam membantu siswa mengatasi masalah kejenuhan belajarnya.

Berdasarkan analisis statistik inferensial tersebut, dapat dianalisis bahwa pada hakikatnya terdapat perubahan tingkat kejenuhan belajar mahasiswa bagi kelompok eksperimen yang diberikan perlakuan teknik ice breaking dalam bimbingan kelompok yakni dengan tingginya kejenuhan belajar yang dialami mahasiswa yaitu berada pada kategori sangat tinggi setelah diberi perlakuan berupa permaian ice breaking tingkat kejenuhan belajarnya mengalami penurunan yang signifikan yaitu berada pada kategori rendah, hal ini dapat dilihat bagaimana mahasiswa mampu mengurangi kejenuhan belajarnya melalui permaian ice breaking dalam bimbingan kelompok. Sedangkan kelompok kontrol yang tidak diberikan teknik ice breaking dalam bimbingan kelompok tidak menunjukkan penurunan yang berarti. Sementara itu, hasil pengujian hipotesis yang menunjukkan adanya pengaruh penerapan teknik ice breaking dalam bimbingan kelompok untuk mengurangi kejenuhan belajar mahasiswa di Institut Pemerintahan dalam Negeri Sulawesi Selatan. Berdasarkan hasil penelitian di atas, tampak bahwa ada pengaruh penerapan teknik ice breaking dalam bimbingan kelompok untuk mengurangi kejenuhan belajar mahasiswa. Terjadinya perubahan tingkat kejenuhan belajar dari kategori sangat tinggi menjadi rendah tidak terlepas dari pengaruh penerapan ice breaking yang dilaksanakan selama tujuh sesi pertemuan dimulai dari pretest sampai dengan posttest.

Menurunnya tingkat kejenuhan belajar mahasiswa pada kelompok eksperimen tidak terlepas dari adanya pengaruh permainan yang perankan dalam kegiatan ice breaking. Adapun jenis permainan yang digunakan oleh peneliti dalam penelitian ini adalah permaian benar-salah, warisan, gemu fami re, satu hati, goyang penguin khatulistiwa. Dari keseluruhan permainan ice breaking yang digunakan dalam penelitian ini dapat dipastikan bahwa adapun nilai-nilai yang dikandung dalam permainan tersebut meliputi nilai kepemimpinan, kerjasama tim, kreatifitas dan konsentrasi belajar. Nilai-nilai dalam permaian ice breaking dapat mengurangi tingkat kejenuhan belajar mahasiswa karena mahasiswa dapat belajar dengan suasana santai, nyaman dan rileks.

Menurut Prijosaksono (2008), alasanalasan lain yang melatari perlunya permainan, adalah: Pada umumnya manusia sangat senang mobilitas, dari pada duduk berdiam diri, bergerak dan dinamis itulah jati dirinya. Manusia dewasa maupun anak-anak sangat membutuhkan pengalaman yang kaya, bervariasi, bermakna sekaligus mengasyikkan. Otak usia anak-anak sangat senang dengan hadirnya sesuatu yang baru, menarik, menantang, dan menakjubkan. Permainan cenderung menstimuli otak, apalagi dengan melibatkan indera manusia secara keseluruhan (visual, audio, dan kinetik). Senada yang dikemukan Mahfud (2010). Melalui kegiatan ice breaking individu mengenal yang lain dan merasa nyaman dengan lingkungan barunya dalam belajar.

Pemberian teknik ice breaking dalam bentuk kegiatan bermain benar-salah ,warisan, gemu fami re, satu hati dan goyang pinguin khatulistiwa dapat meningkatkan konsentrasi mahasiswa dalam belajar karena permainan melalui teknik ice breaking dapat menciptakan suasana yang tidak tegang dalam berinteraksi, membosankan dalam belajar dan akan ada fokus 
perhatian. Teknik ice breaking sebagai teknik bimbingan kelompok diupayakan sebagai teknik untuk mengurangi kejenuhan belajar siswa, karena dengan teknik ice breaking mahasiswa dapat belajar sesuatu tanpa mempelajarinya yang dilakukan melalui sikap saling bekerjasama dan diskusi kelompok, untuk memainkan sebuah permainan yang di lakukan secara bersama-sama.

Secara keseluruhan dapat di simpulkan bahwa terjadinya perubahan tingkat kejenuhan belajar mahasiswa di Institut Pemerintahan Dalam Negeri Sulawesi Selatan dari kategori sangat tinggi menjadi rendah di sebabkan adanya nilai-nilai yang terkandung di dalam permaian ice breaking (benar-salah,warisan, gemu fami re, satu hati dan goyang pingui khatulistiwa) meliputi nilai kepemimpinan, kerjasama tim, kreatifitas dan konsentrasi belajar yang memungkin mahasiswa dapat mengontrol diri dalam belajar menghindari situasi belajar membosankan, mengantuk, menjemukan, dan tegang menjadi rileks, bersemangat, tidak membuat mengantuk, serta ada perhatian dan ada rasa senang untuk mendengarkan atau melihat orang yang berbicara di depan kelas atau ruangan pertemuan.

\section{SIMPULAN DAN SARAN}

Berdasarkan analisa data dan pembahasan hasil penelitian, maka dapat disimpulkan bahwa: (1) Pelaksanaan teknik ice breaking dalam bimbingan kelompok dilakukan melalui tahap persiapan, tahap peralihan, pelaksanaan kegiatan dan tahap pengakhiran termasuk pretest dan posttest. Dalam setiap pelaksanaan ice breaking, mahasiswa mengikuti dengan antusias serta aktif berpartisipasi dalam setiap permainan yang diberikan; (2) Tingkat kejenuhan belajar mahasiswa di Institut Pemerintahan dalam Negeri Sulawesi Selatan sebelum diterapkan teknik ice breaking dalam bimbingan kelompok berada pada kategori sangat tinggi, dan setelah diterapkan teknik ice breaking dalam bimbingan kelompok berada pada kategori rendah; (3) Ada pengaruh yang signifikan terhadap penerapan teknik ice breaking dalam bimbingan kelompok dalam mengurangi kejenuhan belajar mahasiswa di Institut Pemerintahan dalam Negeri Sulawesi Selatan. Artinya, teknik ice breaking dalam bimbingan kelompok dapat mengurangi kejenuhan belajar mahasiswa.

Sehubungan kesimpulan penelitian di atas, maka diajukan saran-saran sebagai berikut: (1) Mengingat teknik ice breaking dalam bimbingan kelompok sebagai teknik bimbingan kelompok dalam kegiatan bimbingan dan konseling belum pernah dilaksanakan di kampus IPDN sulawesi selatan, sedangkan telah terbukti bahwa penerapan teknik ice breaking dalam bimbingan kelompok dapat mengurangi kejenuhan belajar mahasiswa, maka disarankan hendaknya konselor kampus dapat melaksanakan teknik ice breaking dalam bimbingan kelompok secara terprogram dan bekerjasama dengan pihak-pihak yang terkait; (2) Bagi mahasiswa, untuk senantiasa secara mandiri melakukan latihan-latihan berupa teknik ice breaking yang telah diberikan sebelumnya oleh peneliti, sehingga mampu mengatasi masalah belajar khususnya kejenuhan belajar; (3) Kepada rekanrekan mahasiswa dan peneliti, di Jurusan Psikologi Pendidikan dan Bimbingan, agar dapat mengembangkan penerapan teknik ice breaking dalam bimbingan kelompok.

\section{DAFTAR PUSTAKA}

Bakhtiar, M. I. (2015). Pengembangan Video Ice Breaking Sebagai Media Bimbingan Konseling Dalam Meningkatkan Keterampilan Sosial. Jurnal Psikologi Pendidikan dan Konseling: Jurnal Kajian Psikologi Pendidikan dan Bimbingan Konseling, 1 (2): 150-162

Fanani, Ahmad. 2010. Ice Breaking Dalam Proses Belajar Mengajar. Jurnal Volume VI Nomor 11.

Fatmawati. 2018. Hubungan Antara Kejenuhan Belajar Dengan Stres Akademik (Pada Siswa-Siswi Full Day School Di Smpn 2 Samarinda). Jurnal Psikologi Fisip Ummul Vol 6 No. 4.

Febriandari, Efi \&dkk. 2018. Pengaruh Kreativitas Guru Dalam Menerapkan Ice Breaking Dan Motivasi Belajar Terhadap Hasil Belajar Siswa Sekolah Dasar. Jurnal Riset Dan Konseptual Vol.3 No.4

Hakim, Thursan. 2004. Mengatasi Gangguan Mental Dan Fisik. Jakarta: Puspa Aswara.

Kurniasih. 2015. Penerapan Ice Breaking (Penyegar Pembelajaran) Untuk 
177 | JURKAM: Jurnal Konseling Andi Matappa Vol 4, No 2, Agustus 2020

Meningkatkan Hasil Belajar Ipa Siswa Kelas IIIA Mts An-Nur Pelopor Bandarjaya Tahun Pelajaran 2013/2014.Jurnal Pendidikan Fisika, Vol. 3 No. 1

Nurihsan, Achmad Juntika. 2006. Bimbingan dan Konseling dalam Berbagai Latar Kehidupan. Bandung : PT. Refika Aditama.

Setianingsih, Eka \& dkk. 2014. Pengembangan Model Bimbingan Kelompok Teknik Pemecahan Masalah Untuk Meningkatkan Keterbukaan Diri Siswa. Jurnal Bimbingan Dan Konseling Vol.3 No.2

Soenarno, A. 2007. Ice Breaker Don't Be Tegang Untuk Pelatihan Manajemen. Yoyakarta: Andi Yogyakarta.
Sugara. 2011. Efektifitas Teknik Self-Instruction dalam Menangani Kejenuhan Belajar Siswa di Mts Roudlotul Ulum Jatirejo Mojokerto. Jurnal BK UNESA, Volume 4 Nomor 1.

Sumardani. 2014. Pengaruh Penerapan Teknik Ice Breaker Terhadap Hasil Belajar Peserta Didik Kelas III Sekolah Dasar.Jurnal Pendidikan Dan Pembelajaran Khatulistiwa, Vol.3 No.10

Suryoharjo, Kusumo. 2012. 100+ Ice Breaker PenyemangatBelajar: Kiat Praktis Menghadirkan Suasana Belajar Segar dan Heboh. Yogyakarta. Penerbit Ilman Nafia.

Syam, Mahfud. 2010. "Ice Breaking Definition”. 